\title{
Nearest-neighbor effects modulate loxP spacer DNA chemical shifts and guide oligonucleotide design for NMR studies
}

Authors: Nicole Wagner ${ }^{1}$, Mark P. Foster ${ }^{1^{*}}$

1Department of Chemistry and Biochemistry, The Ohio State University, Columbus, Ohio, USA 43210.

*Corresponding Author: Mark P. Foster (email: foster.281@osu.edu; 614-292-1377)

Department of Chemistry and Biochemistry, The Ohio State University, Columbus, Ohio, USA 43210.

\section{Supporting Information}

\section{Table of Contents}

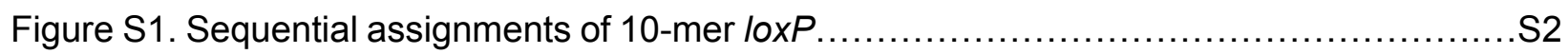

Figure S2. Use of thymine $\mathrm{H} 7$ and cytosine $\mathrm{H} 5$ protons to support sequential assignments........S3

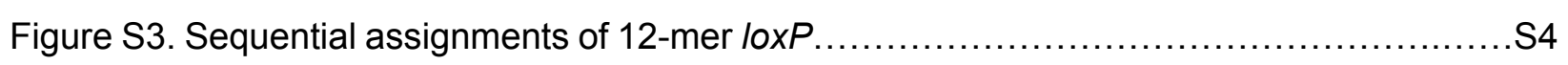

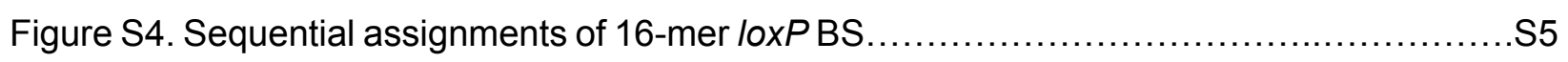

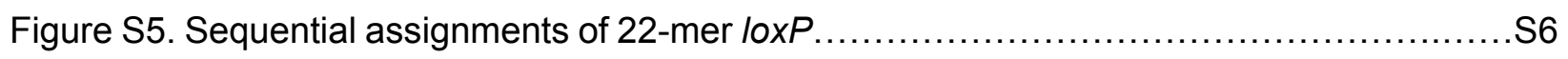

Figure S6. Differences between observed and predicted loxP chemical shifts....................S7

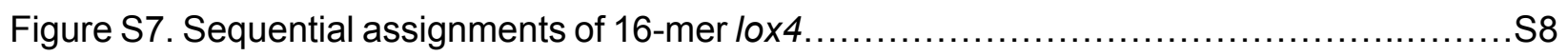

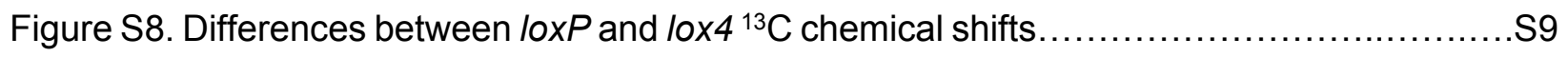

Figure S9. Differences between observed and predicted lox4 chemical shifts................S10

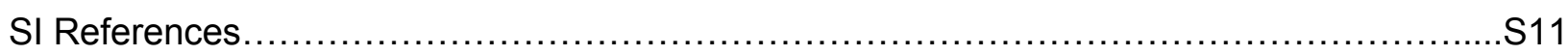



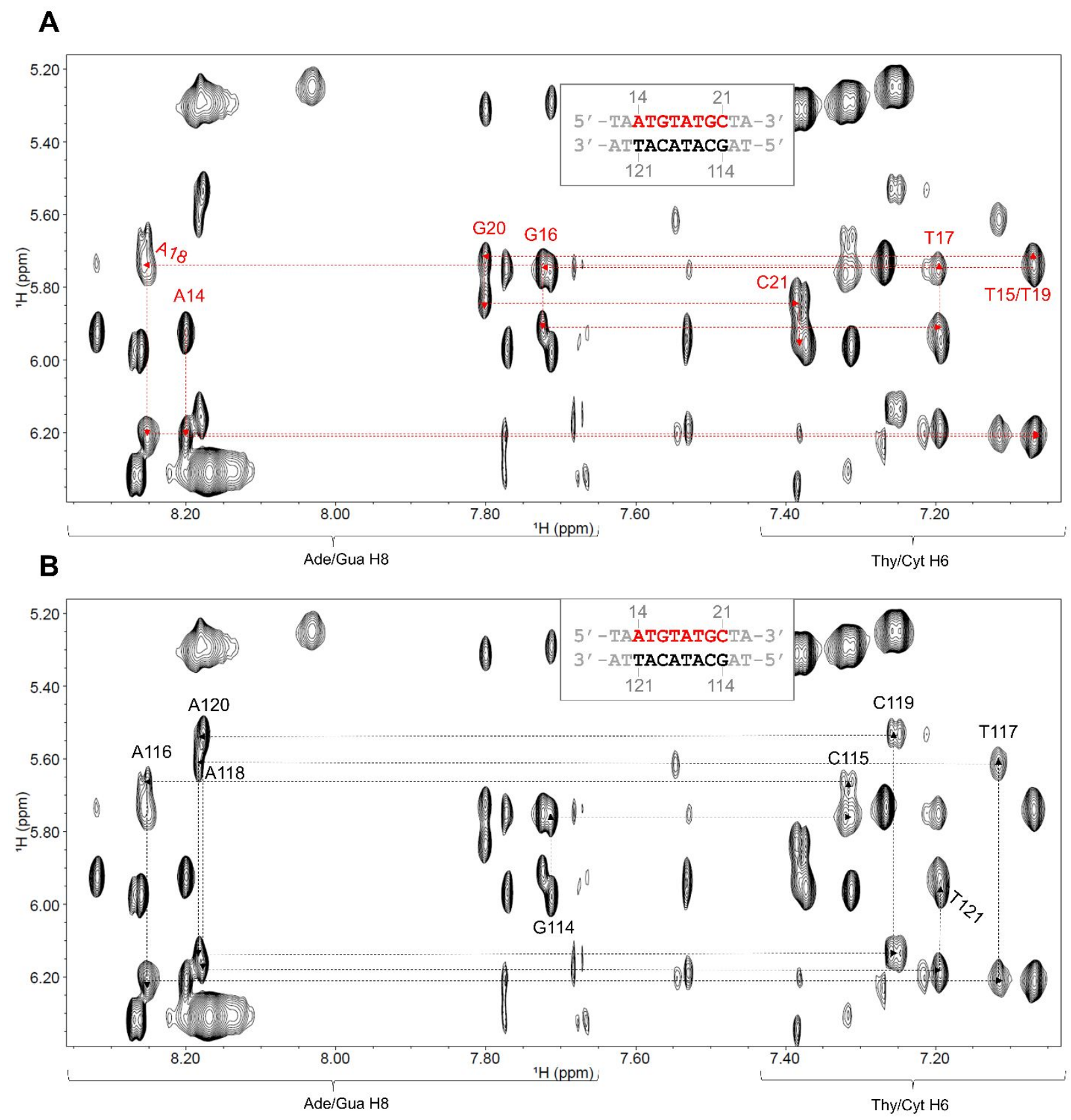

Figure S1. Base $\mathrm{H} 6 / \mathrm{H} 8$ to $\mathrm{H} 1$ ' region of the $2 \mathrm{D}$ NOESY spectrum illustrating sequential resonance assignments of the 10-mer loxP spacer construct. Labels indicate the residue to which the $\mathrm{H} 6$ or $\mathrm{H} 8$ belongs. The numbering scheme is shown in the inset. A) Top strand assignments. B) Bottom strand assignments. 


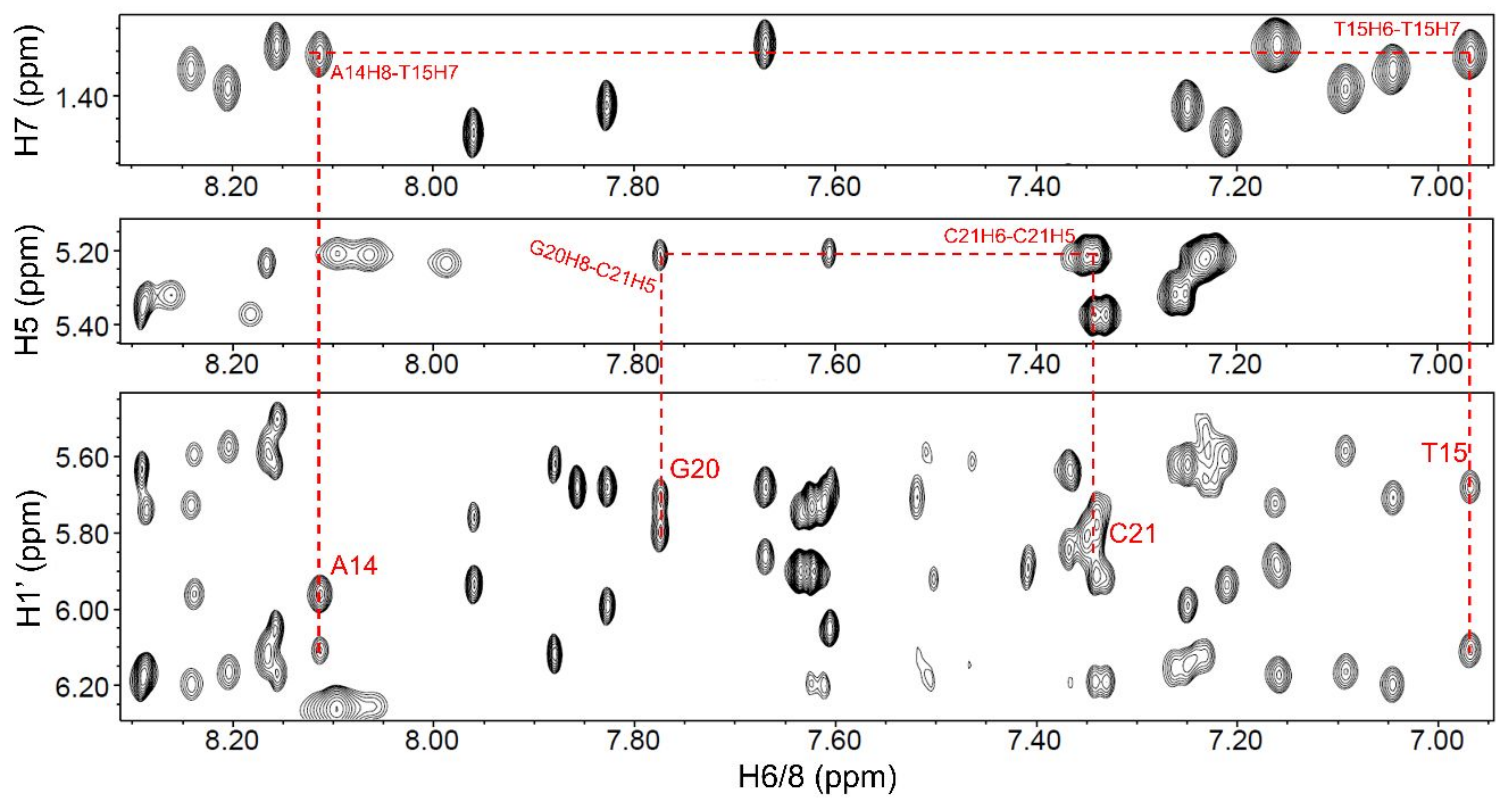

Figure S2. Use of thymine $\mathrm{H} 7$ and cytosine $\mathrm{H} 5$ protons to support sequential assignments, demonstrated with the IoxP 16-mer spectrum. Each thymine $\mathrm{H} 7$ (methyl group) NOEs to its own $\mathrm{H} 6$ and to the $\mathrm{H} 6 / \mathrm{H} 8$ of the preceding (5') residue. Shown here, NOEs from $\mathrm{T} 15 \mathrm{H} 7$ to both $\mathrm{T} 15 \mathrm{H} 6$ and $\mathrm{A} 14 \mathrm{H} 8$. Each cytosine $\mathrm{H} 5$ proton NOEs to its own $\mathrm{H} 6$ proton (with splitting due to J-coupling in the $\mathrm{H} 6-\mathrm{H} 5$ crosspeak) and to the $\mathrm{H} 6 / \mathrm{H} 8$ of the preceding (5') residue. Shown here, NOEs from $\mathrm{C} 21 \mathrm{H} 6$ to $\mathrm{C} 21 \mathrm{H} 5$ and $\mathrm{G} 2 \mathrm{OH} 8$. 

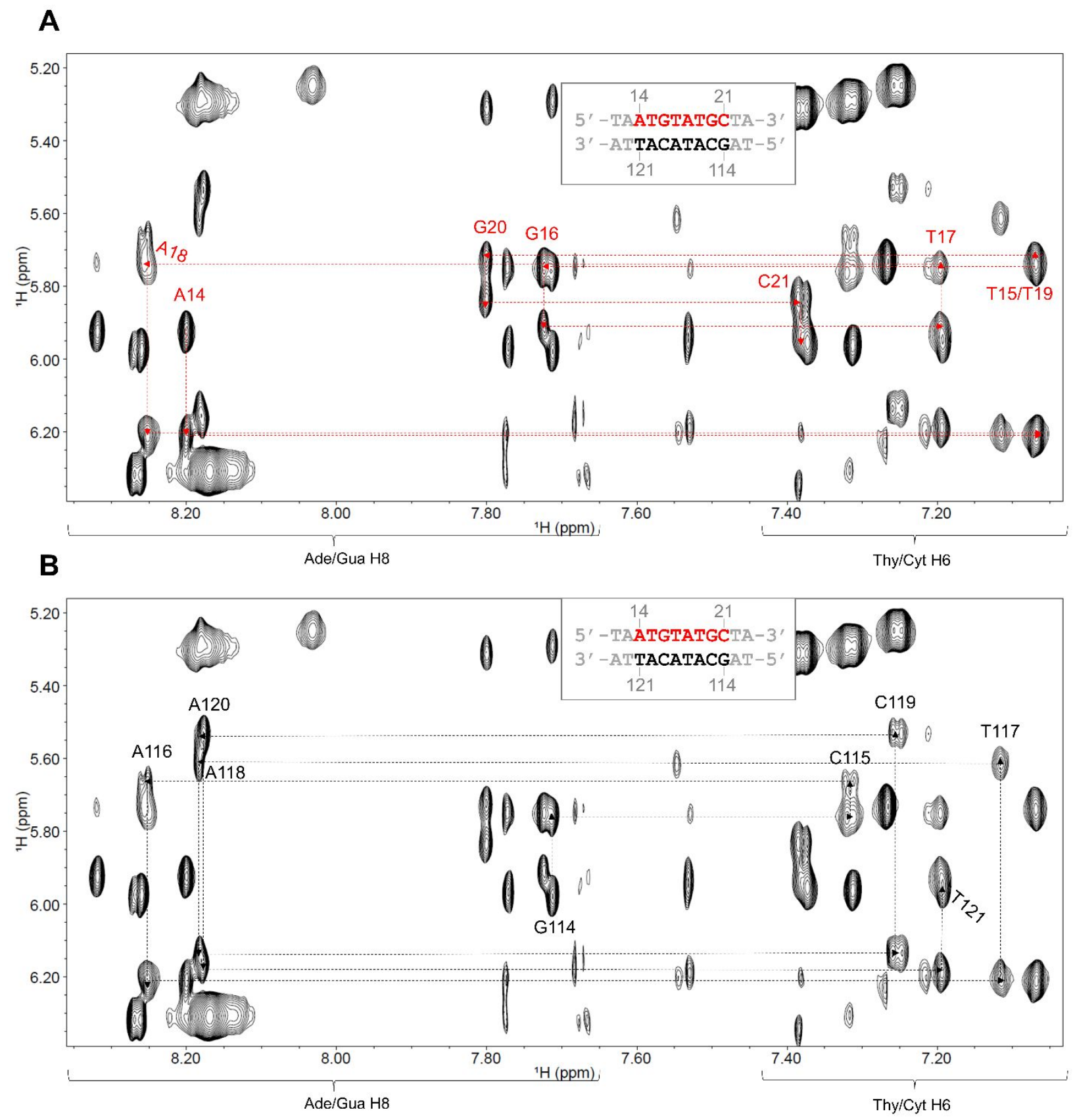

Figure S3. Sequential resonance assignments of the 12-mer loxP construct. Residue labels indicate the residue to which the $\mathrm{H} 6$ or $\mathrm{H} 8$ belongs. The numbering scheme is shown in the inset. A) Top strand assignments. B) Bottom strand assignments. 


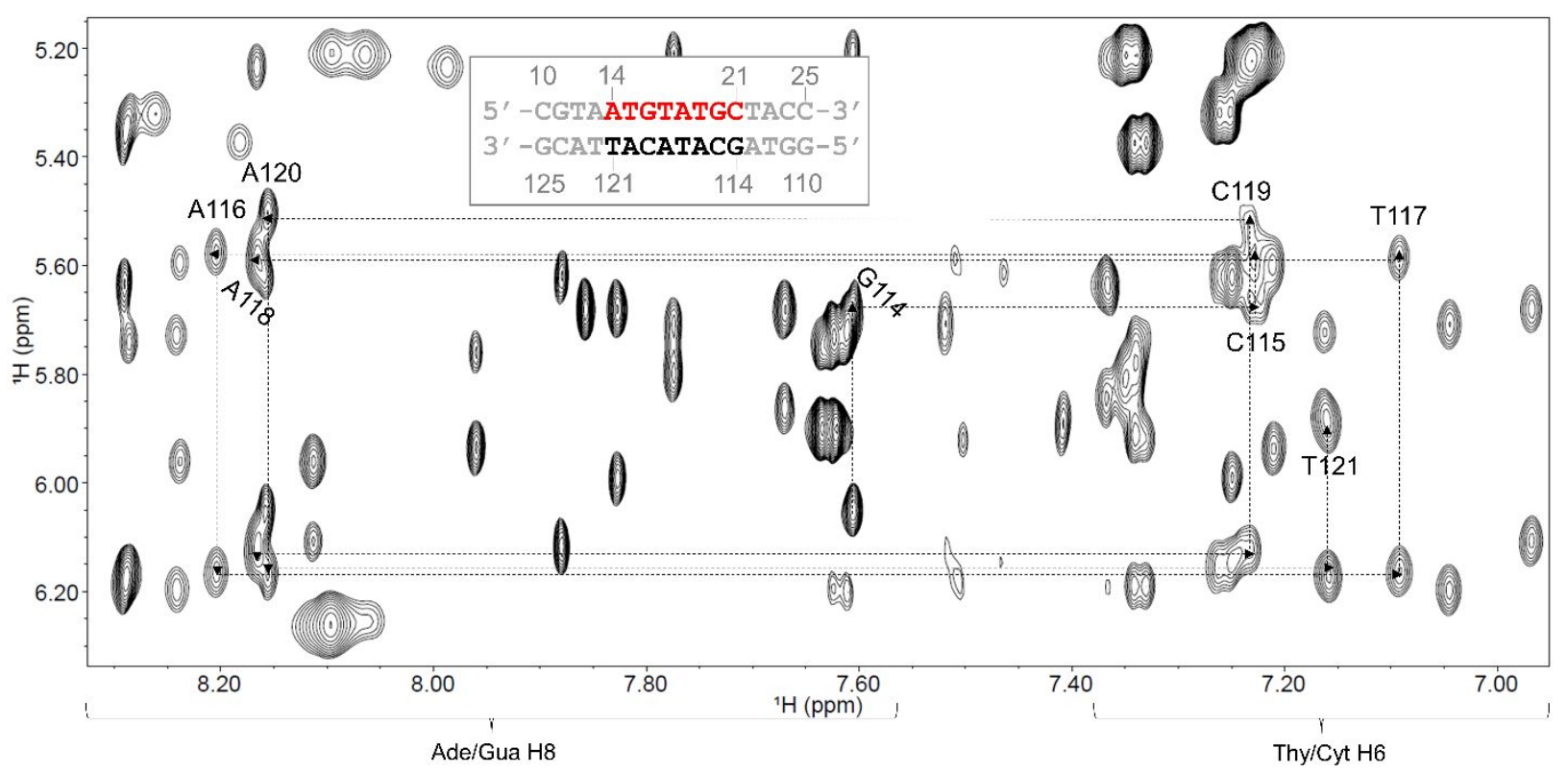

Figure S4. Base $\mathrm{H6} / \mathrm{H} 8$ to $\mathrm{H} 1$ ' region of the 2D NOESY spectrum illustrating sequential resonance assignments of the bottom stand (BS) of the 16-mer loxP spacer construct. Labels indicate the residue to which the $\mathrm{H} 6$ or $\mathrm{H} 8$ belongs. The numbering scheme is shown in the inset. 

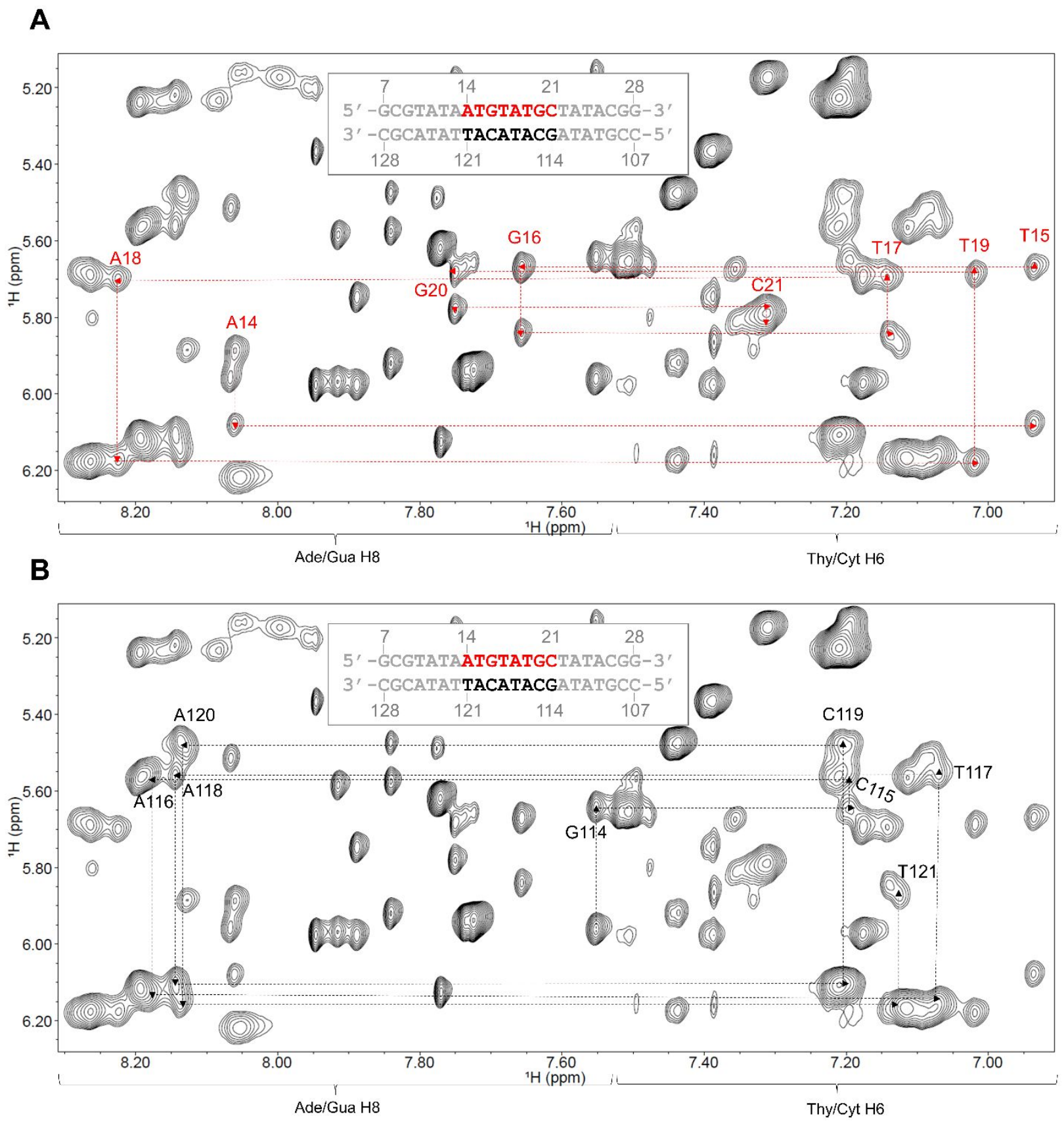

Figure S5. Sequential resonance assignments of the 22-mer loxP construct. Residue labels indicate the residue to which the $\mathrm{H} 6$ or $\mathrm{H} 8$ belongs. The numbering scheme is shown in the inset. A) Top strand assignments. B) Bottom strand assignments. 
A

H6/8, B-form duplex predictions

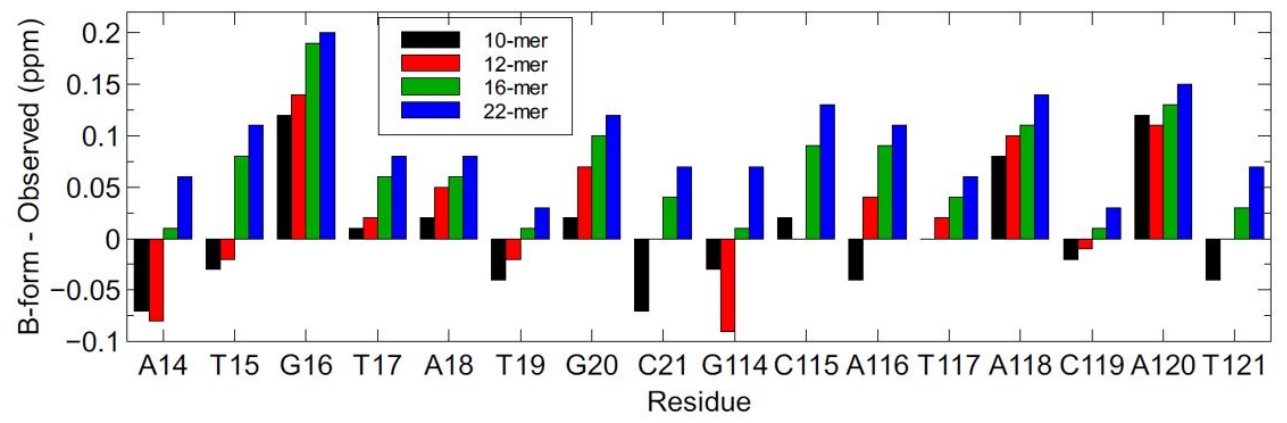

H1', B-form duplex predictions

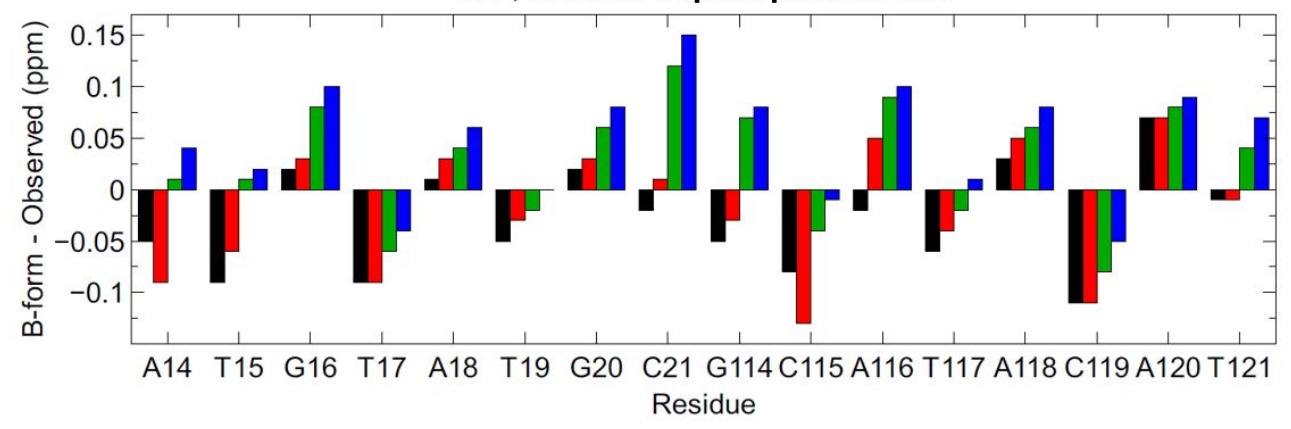

B
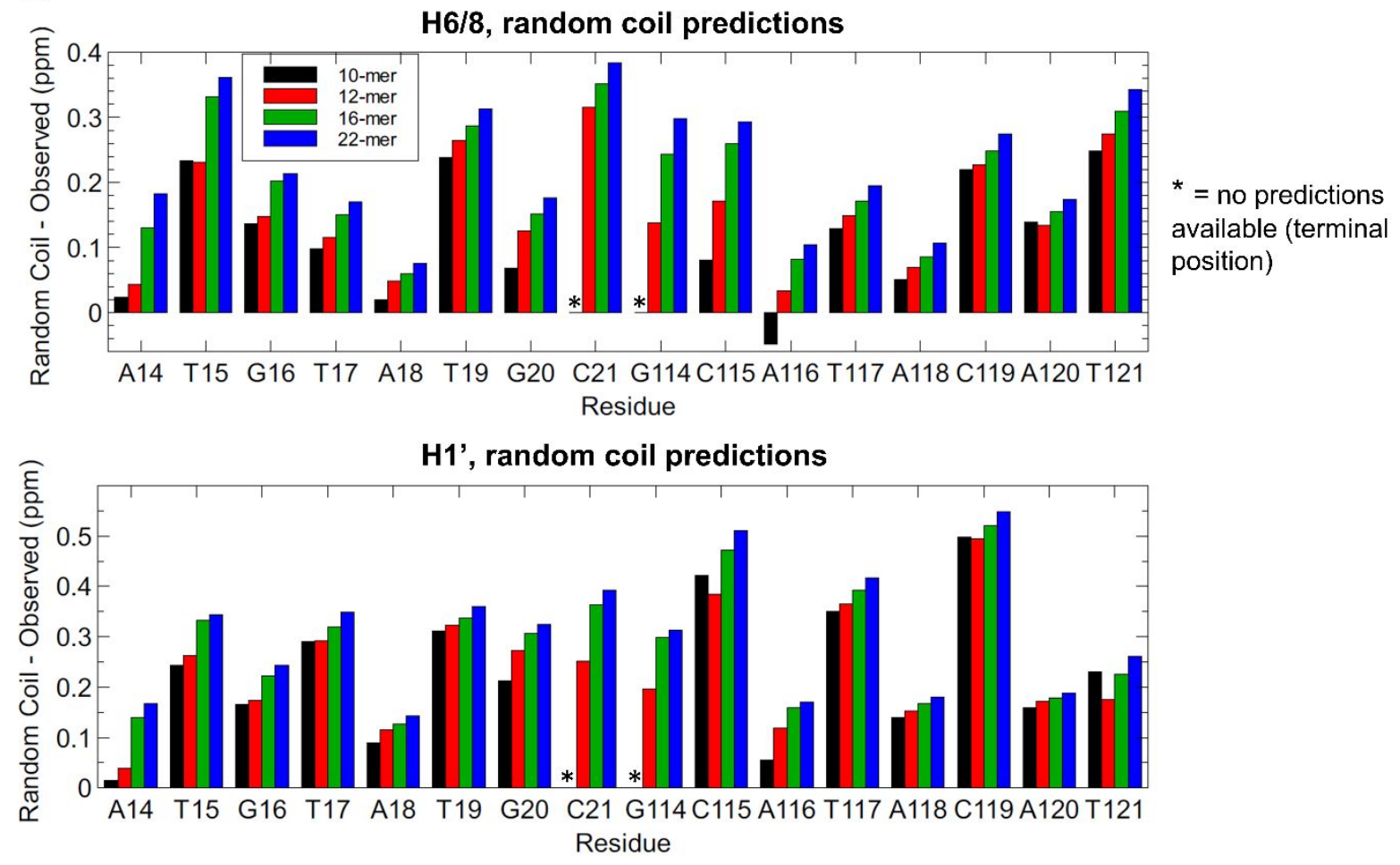

Figure S6. A) Differences between observed loxP chemical shifts and predicted double-helical B-form chemical shifts calculated with DSHIFT using the Altona method ${ }^{1,2}$. B) Differences between observed loxP chemical shifts and predicted random coil chemical shifts calculated with DSHIFT ${ }^{1,3}$. 

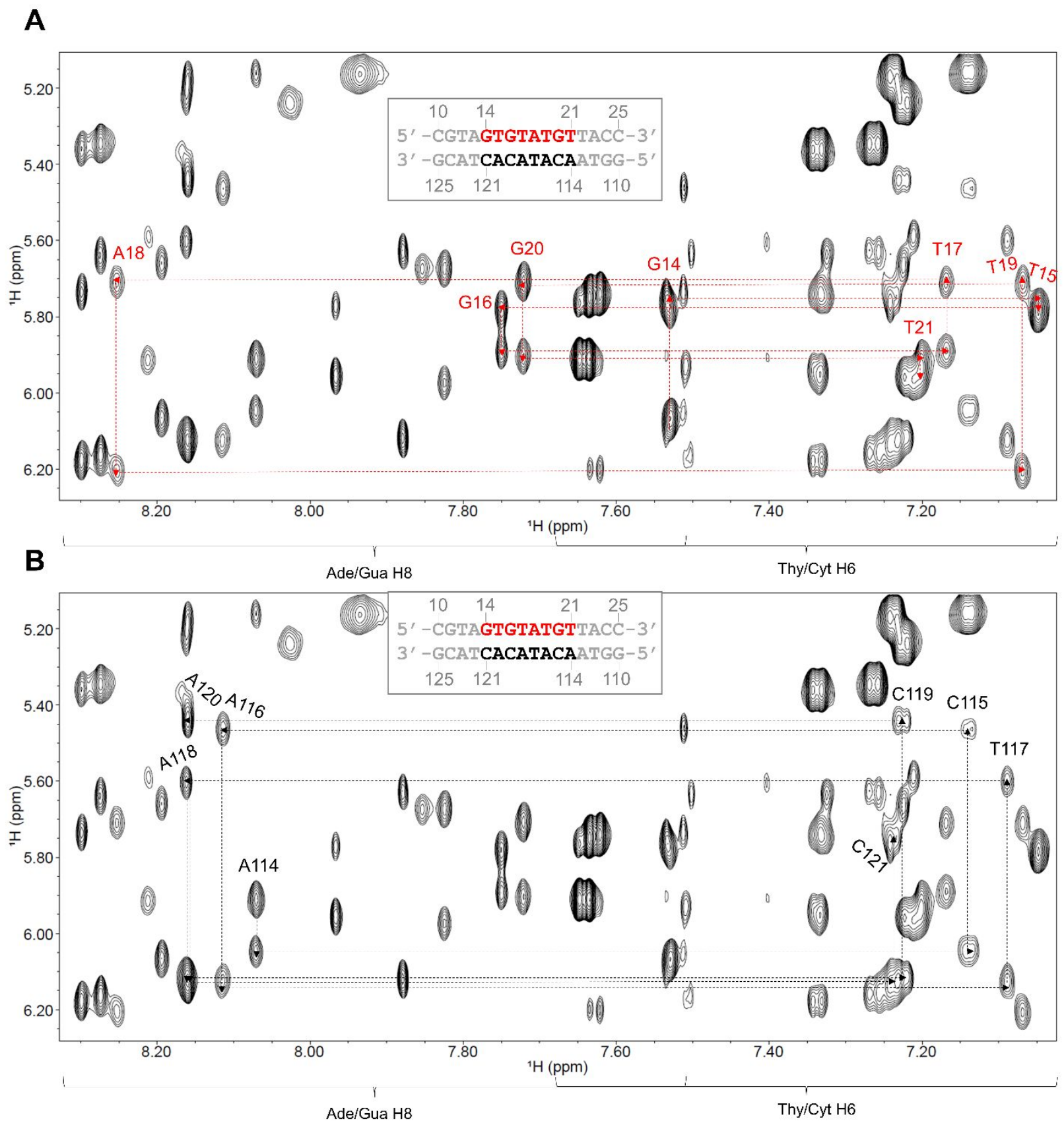

Figure S7. Sequential resonance assignments of the 16-mer lox 4 construct. Residue labels indicate the residue to which the $\mathrm{H} 6$ or $\mathrm{H} 8$ belongs. The numbering scheme is shown in the inset. A) Top strand assignments. B) Bottom strand assignments. 

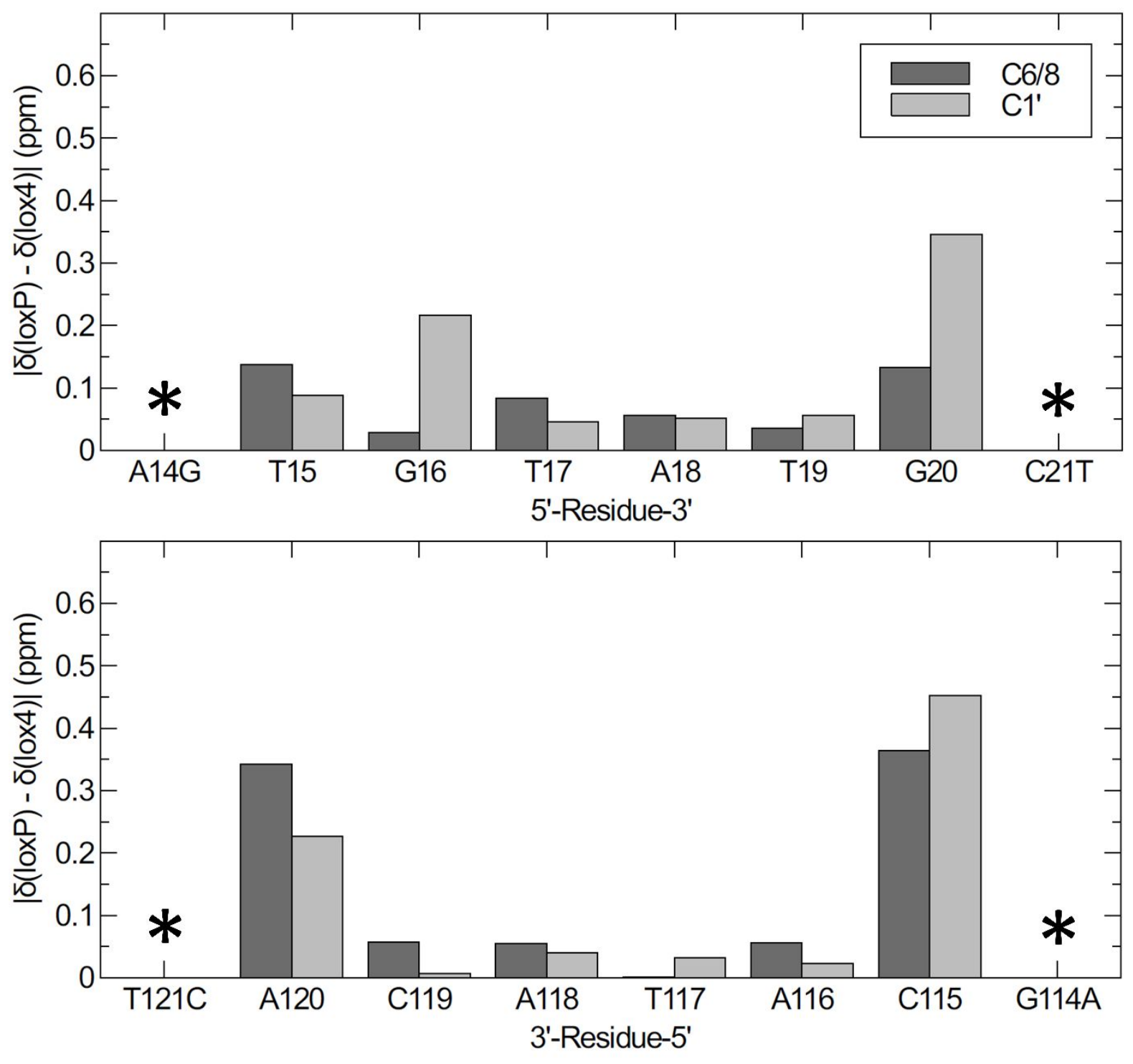

Figure S8. ${ }^{13} \mathrm{C} \Delta \delta$ values of the lox 4 spacer relative to loxP, shown as bar graphs. Asterisks denote mutated positions. TS values are shown in the top plot; BS values are plotted below such that base-paired partners are directly across from one another. 
A
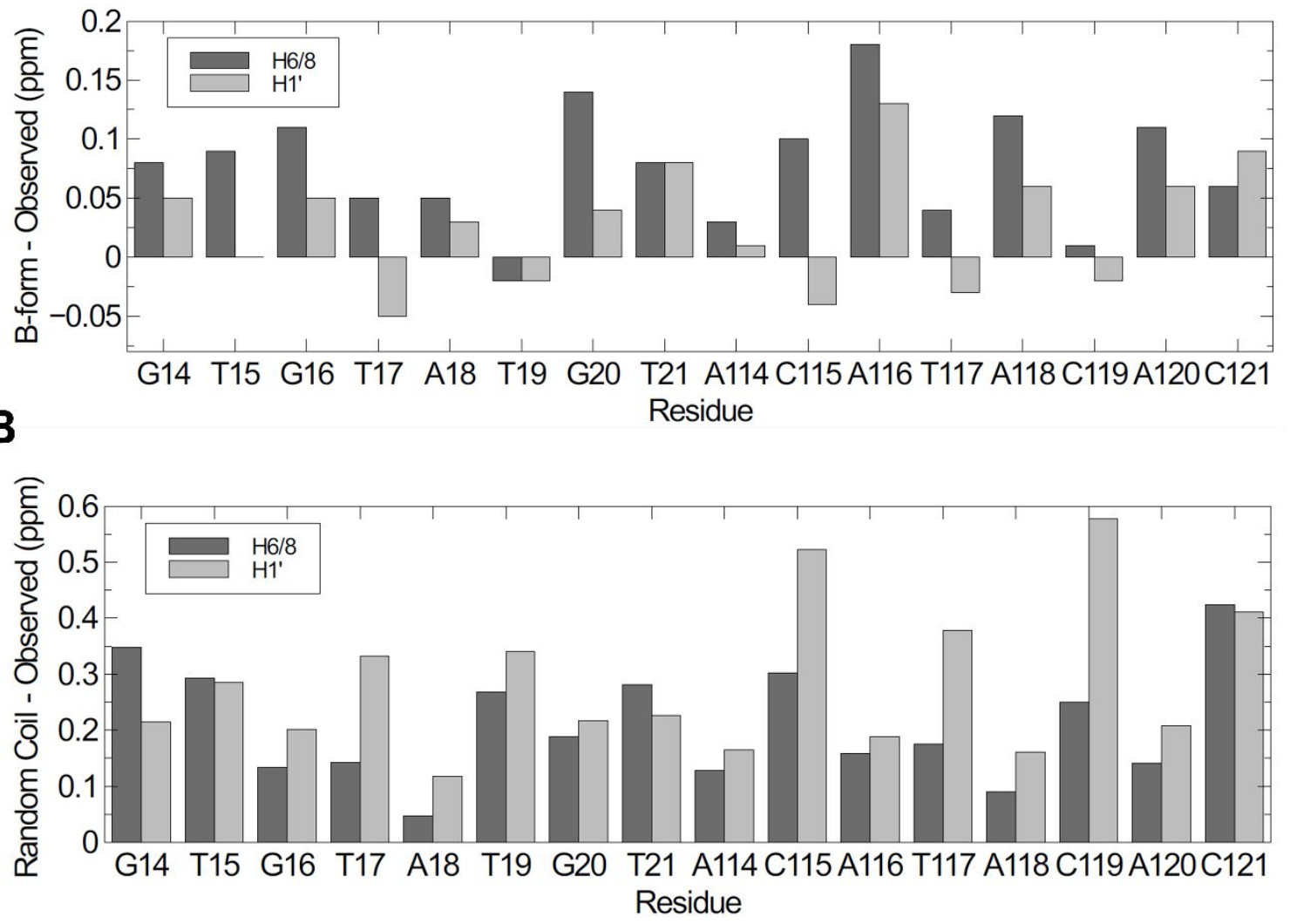

Figure S9. A) Differences between observed lox $4{ }^{1} \mathrm{H}$ chemical shifts and predicted double-helical B-form chemical shifts calculated with DSHIFT using the Altona method ${ }^{1,2}$. B) Differences between observed lox 4 chemical shifts and predicted random coil chemical shifts calculated with $\mathrm{DSHIFT}^{1,3}$. 


\section{Supporting Information References}

(1) Lam, S. L. DSHIFT: A Web Server for Predicting DNA Chemical Shifts. Nucleic Acids Res. 2007, 35, 713-717. https://doi.org/10.1093/nar/gkm320.

(2) Altona, C.; Faber, D. H.; Hoekzema, A. J. A. W. Double-Helical DNA 1H Chemical Shifts: An Accurate and Balanced Predictive Empirical Scheme. Magn. Reson. Chem. 2000, 38 (2), 95-107. https://doi.org/https://doi.org/10.1002/(SICl)1097458X(200002)38:2<95::AID-MRC592>3.0.CO;2-M.

(3) Lam, S. L.; Ip, L. N.; Cui, X.; Ho, C. N. Random Coil Proton Chemical Shifts of Deoxyribonucleic Acids. Journal of Biomolecular NMR. KLUWER/ESCOM December 1, 2002, pp 329-337. https://doi.org/10.1023/A:1021671531438. 